\title{
The effect of grass species on nitrogen response in grass clover swards
}

\section{T J Gilliland ${ }^{1}$, A D Farrell ${ }^{2}$, D McGilloway ${ }^{3}$, D Grogan ${ }^{3}$}

${ }^{1}$ Agri-Food and Biosciences Institute, Belfast, United Kingdom, ${ }^{2}$ Queens University Belfast, Belfast, United Kingdom,

${ }^{3}$ Department of Agriculture, Fisheries and Food, Kildare, Ireland

Email: aidanfarrell@yahoo.com

Introduction Changes to EU regulations and increased fertiliser costs have resulted in reduced nitrogen $(\mathrm{N})$ use in grassland systems. This has implications for the choice of grass variety sown by growers. Currently, Irish grasslands are populated with varieties bred to produce high yields under optimum $\mathrm{N}$ conditions. Such swards are largely dominated by Perennial Ryegrass, however, as $\mathrm{N}$ levels are reduced it is uncertain whether this will remain the most productive species. This study compares the performance of Perennial Ryegrass to that of four alternative species grown at different $\mathrm{N}$ levels.

Material and methods From 2006 to 2009, six forage grasses, Cocksfoot (Donata), Meadow Fescue (Pradel), Tall Fescue (Barolex), Timothy (Dolina), diploid Perennial Ryegrass (Portstewart) and tetraploid Perennial Ryegrass (Navan), were grown along with a companion white clover (Chieftain) at Crossnacreevy Plant Testing Station, Belfast. Plants were grown at three $\mathrm{N}$ levels: high $\left(420 \mathrm{~kg} \mathrm{ha}^{-1} \mathrm{~N}\right)$, medium $\left(210 \mathrm{~kg} \mathrm{ha}^{-1} \mathrm{~N}\right)$ and low $\left(105 \mathrm{~kg} \mathrm{ha}^{-1} \mathrm{~N}\right)$. Trial plots measured $1.5 \mathrm{~m} \mathrm{x} 7 \mathrm{~m}$ and were replicated three times within each treatment in a randomised block design. Each treatment was managed to maximise dry matter yield, with a target of 10 cuts per season using a nominal regrowth period of $21 \mathrm{~d}$ with periods of up to $35 \mathrm{~d}$ towards the end of the season. Plot fresh weight was determined by harvesting the entire plot to a stubble height of $5 \mathrm{~cm}$ using a plot harvester (Haldrup, Logstor, Denmark). A random subsample of c. $250 \mathrm{~g}$ was taken from each plot for dry weight determination after oven drying at $80^{\circ} \mathrm{C}$ for $16 \mathrm{~h}$. Botanical composition was also determined for two cuts each year by taking a subsample from each plot. Average dry matter yields over the three years were compared using two-way ANOVA (Genstat 8; VSN International Ltd., Hemel Hempstead, UK).

Results In year one, yields were low and there was a clear pattern between treatments with lower $\mathrm{N}$ levels resulting in lower yields and higher clover contents. Yields improved in subsequent years, however, in low and medium $\mathrm{N}$ plots clover content also increased and by year three clover typically accounted for more than $50 \%$ of the yield. Table 1 shows the total plot yield over the season (up to $30^{\text {th }}$ October) averaged over the three years. There were significant differences between $\mathrm{N}$ levels, between species and for $\mathrm{N}$ level $\mathrm{x}$ species. Generally, tetraploid perennial ryegrass plots were the highest yielding at high $\mathrm{N}$, but showed the largest decrease where $\mathrm{N}$ was limited. The diploid perennial ryegrass plots were more tolerant to the low and medium $\mathrm{N}$ conditions, with yields similar to or greater than Fescue and Cocksfoot plots. Timothy plots outperformed all of the others, especially under the low and medium $\mathrm{N}$ conditions. The botanical separations showed that much of the yield differences were due to differences in clover yield rather than yield of the sown grass species. In addition, Timothy and Cocksfoot plots were particularly prone to encroachment from other grasses.

Table 1 Average yield (dry matter $\mathrm{tha}^{-1} \mathrm{y}^{-1}$ ) of six grass clover swards at three Nitrogen levels (data in parenthesis shows the range of yields over three years)

\begin{tabular}{lllc}
\hline \hline & \multicolumn{3}{c}{ Nitrogen $\left(\mathrm{kg} \mathrm{ha}^{-1}\right)$} \\
P. Ryegrass (4n) & \multicolumn{1}{c}{105} & \multicolumn{1}{c}{210} & 420 \\
\cline { 2 - 4 } P. Ryegrass (2n) & $8.2(6.1-10.2)$ & $8.8(6.3-11.8)$ & $12.9(10.9-16.7)$ \\
Timothy & $8.9(7.8-10.2)$ & $9.4(6.8-12.1)$ & $12.2(10.2-16.0)$ \\
T. Fescue & $8.6(7.8-9.2)$ & $10.3(8.9-12.3)$ & $13.0(11.6-15.3)$ \\
M. Fescue & $8.8(7.9-9.7)$ & $9.1(7.7-10.0)$ & $12.5(11.3-14.6)$ \\
Cocksfoot & $7.9(4.8-10.0)$ & $8.5(5.5-11.2)$ & $12.2(11.0-14.6)$ \\
\hline
\end{tabular}

Conclusion Reducing $\mathrm{N}$ reduced plot yields and increased clover content for all of the species tested, this in general agreement with other studies (Frame et al. 1998). In this case, clover came to dominate all of the low N swards regardless of the choice of sown species. The results suggest that swards based on diploid perennial ryegrass may be more tolerant to low $\mathrm{N}$ than those based on tetraploid perennial ryegrass. There may also be potential to improve yields at low $\mathrm{N}$ by including alternative species, such as Timothy, but the interaction with clover and other grasses needs to be considered.

\section{References}

Frame J., Charlton J.F.L. and Laidlaw A.S. 1998. Temperate Forage Legumes. Wallingford, UK. CAB International. 